\title{
SENTIDOS PARA ATIVIDADES DE LEITURA E ESCRITA EM ESCOLAS DE ENSINO FUNDAMENTAL
}

\author{
Jeice Campregher ${ }^{1}$ \\ Osmar de Souza ${ }^{2}$
}

\section{RESUMO}

Este artigo apresenta as contribuições de um Programa de Extensão da FURB - Universidade Regional de Blumenau. O Programa, até 2008, era intitulado Sentidos para atividades de leitura e escrita na escola - este artigo corresponde a um olhar sobre o desenvolvimento do Programa em dois anos: 2007 e 2008. As comunidades contempladas são escolas públicas de Blumenau, mais precisamente, turmas de quartas-séries do Ensino Fundamental. No primeiro contato com as turmas, foram entregues questionários, objetivando perceber o conhecimento das crianças com relação aos temas propostos (comunidade e família). Nas outras visitas uma por semana -, foram desenvolvidas atividades de leitura e escrita. Os alunos foram, ainda, convidados a pesquisar: na biblioteca, questionando parentes ou moradores da rua em que moram. Um dos resultados - apresentados mais detalhadamente ao longo do artigo - é a ampliação do conhecimento sobre história local - tanto por parte dos alunos e professores, quanto por parte dos acadêmicos envolvidos. Apesar de haver objetivos propulsores do Programa - como "criar condições para que alunos de quartas-séries leiam e escrevam textos, mais precisamente sobre questões familiares e comunitárias" -, uma das conclusões, com relação ao desenvolvimento do Programa, é a possibilidade de contribuir nas dimensões institucional, acadêmica e social. Muitas vezes essas contribuições podem nem ser imaginadas ao se idealizar um Programa.

Palavras-chave: Comunicação. Universidade. Comunidade. Dimensões.

\footnotetext{
${ }^{1}$ Mestranda em Educação da FURB. jeice campregher@yahoo.com.br

${ }^{2}$ Graduado e especializado em Letras, mestre em Sociologia Política pela Fundação Escola de Sociologia e Política de São Paulo, doutor em Letras pela Universidade Estadual Paulista Júlio de Mesquita Filho. Atualmente é professor titular do Fundação Universidade Regional de Blumenau. Tem experiência na área de Educação, com ênfase em Linguística. osmar@furb.br/souza.osmars@gmail.com
} 


\title{
SENSES FOR READING AND WRITING ACTIVITIES AT SCHOOLS OF FUNDAMENTAL TEACHING
}

\begin{abstract}
This article have to present the contributions of a Extension Program of FURB - Regional University of Blumenau. The Program, until 2008, was entitled "Senses for reading and writting activities at school" - this article corresponds to a glance on the development of the Program in two years: 2007 and 2008. The contemplated communities are public schools of Blumenau, more precisely, groups of fourth series of the Fundamental Teaching. In the first contact with the groups, questionnaires were hand out to students, aiming to notice the children's knowledge regarding the proposed themes (community and family). In the other visits - one per week -, reading and writting activities were developed. The students were, still, guests to research: in the library, questioning relatives or residents of the street in that they live. One of the results - that will be presented in full detail along the article - is the enlargement of the knowledge on local history - for students, teachers and academics involved. In spite of there are objectives propellers of the Program - as "to create conditions to students of fourth series read and write texts, more precisely about family and community -, one of the conclusions, regarding the development of the Program, is the possibility to contribute in the dimensions institutional, academic and social. Sometimes, those contributions can't be imagined when a Program is idealized.
\end{abstract}

Keywords: communication; University; community; dimensions.

\section{INTRODUÇÃO}

Este artigo discute as diversas possibilidades de acréscimo que um Programa de extensão, inserido em salas de aula, pode trazer às dimensões social, acadêmica e institucional. O Programa em questão é intitulado "Sentidos para atividades de leitura e escrita na escola"3. O citado Programa concorreu a um edital interno da Universidade

\footnotetext{
${ }^{3}$ Adiante, no artigo, verá que havia dois projetos vinculados ao Programa. A partir de 2009, foi dada continuação somente ao projeto que desenvolve atividades de leitura e escrita de histórias familiares - o único motivo é a quantidade de bolsistas - 
Regional de Blumenau, e seu desenvolvimento se deu durante os anos de 2007 e 2008 . O artigo iniciará apresentando sua concepção de extensão, que se apoia em Botomé (1996) e Freire (1977).

Segundo Botomé (1996, p. 36), “a extensão pode ser vista como uma parte do fazer humano que é realizado pela Universidade”. No entendimento do mesmo autor e também de Freire, as atividades desenvolvidas pela extensão universitária devem envolver um processo de troca de informações e coordenação de atividades entre a Universidade e os contextos extra-acadêmicos. Para os autores, o termo "extensão" deveria ser substituído pela expressão "comunicação com a sociedade", o que pressupõe uma via de mão dupla, ou seja, que a interação possibilite transformações tanto nas comunidades externas quanto na comunidade acadêmica. Botomé (1996, p.25) acrescenta que, para ser intitulada "instituição", é necessário que haja uma organização de "pessoas em torno de um esforço coletivo de interesse do conjunto da sociedade [e] em função do que é necessário e importante ser realizado pela instituição para o todo onde ela está inserida.

A Universidade tem alunos de todo o Vale do Itajaí, contudo, Blumenau é o núcleo e, também, é onde se localizam as escolas abrangidas pelo Programa. Se Botomé fala em realizações da instituição "para o todo onde ela está inserida", para contextualizar esse "todo", ao menos, deve-se contextualizar a cidade de Blumenau. Até porque o Vale do Itajaí, ou seja, as cidades vizinhas, têm uma história bastante semelhante. Machado (2008, p.14) descreve que a cidade de Blumenau foi, "a princípio, idealizada como uma colônia particular com fins de assentamento de colonos imigrantes, vindos inicialmente da ainda não formada Alemanha a partir de 1850". Tal Colônia, então, "atraiu colonos para a produção em pequenas propriedades [...]. Somente em 1880, [ela] teve autonomia, na medida em que se constituiu como Vila e, em 1883, como municipalidade.

O contexto em que a FURB - Fundação Universidade Regional de Blumenau - está inserida é o que justifica as ações do Programa em questão. Atualmente, as marcas dessas culturas na cidade podem ser observadas mais facilmente em bairros mais afastados da área central. Nesses bairros, estão localizadas as escolas mais antigas da cidade - às quais se deu prioridade, visto que o principal objetivo do Programa é permitir que alunos de quartas-séries leiam e escrevam textos sobre questões familiares e comunitárias - o que será relatado mais adiante. 
O Programa de Extensão "Sentidos para atividades de leitura e escrita na escola" tem como base outro similar, na Universidade do Minho, Uminho, em Braga, Portugal, em que alunos de camadas populares resgatam a história de seus nomes. O Coordenador do Programa de Extensão da FURB tomou conhecimento das atividades que estavam ocorrendo em Portugal quando Maria de Lourdes Dionísio, a professora responsável, veio à FURB.

\section{MATERIAL E MÉTODOS}

O Programa desenvolvido em Blumenau é financiado pela FURB, através da bolsa fornecida à extensionista - acadêmica de Letras - e pagamento das horas do professor coordenador vinculado ao Departamento de letras departamento de Educação pela PROPEX/DAEX ("Pró-Reitoria de Pesquisa, Pós-Graduação e Extensão" e "Divisão de Apoio à Extensão"), com o apoio do Centro de Ciências da Educação.

O público-alvo são escolas municipais e estaduais da cidade, mais precisamente, alunos de quartas-séries do Ensino Fundamental - antes de vigorar a lei dos nove anos - e, indiretamente, os (as) professores (as) das turmas - o termo "indiretamente" será explicado adiante". Os projetos vinculados a ele - (1) Ler e escrever histórias familiares e (2) Ler e escrever histórias de comunidades - estão em desenvolvimento há dois anos, sendo que sete unidades escolares foram contempladas com as ações do Programa. No primeiro semestre de 2008, o Programa contou com o apoio de uma voluntária do Artigo 170, e, no segundo semestre do mesmo ano, teve apoio de 3, duas do 170, todas acadêmicas de Letras.

Como foi brevemente pontuado, a principal finalidade do Programa é criar condições para que alunos de quartas-séries leiam e escrevam textos, mais precisamente sobre questões familiares e comunitárias. Esse objetivo vai ao encontro da afirmação de Geraldi (1997, p. 76): “é preciso que as aulas e as seqüências sejam capazes, por um lado, de considerar o saber do próprio aluno (porque ele é já falante da língua) e por outro lado criar as condições mais favoráveis para o exercício da língua (principalmente em sua modalidade escrita)".

Objetiva-se devolver às escolas, na forma de pequenas apostilas, materiais produzidos pelos alunos e, também, os coletados, para que possam ser utilizados posteriormente (tais materiais estão em fase de conclusão); além disso, o Programa visa que os alunos redijam textos de acordo com o gênero do discurso específico. No caso do Projeto (1) Ler e escrever histórias familiares, o gênero é o relato-interpretativo. No caso do (2) Ler e escrever histórias de comunidades, o gênero é o relato-histórico. Entende-se "gênero do discurso" segundo a 
definição de Backtin: “evidentemente, cada enunciado particular é individual, mas cada campo de utilização da língua elabora seus tipos relativamente estáveis de enunciados, os quais denominamos gêneros do discurso" (2003, p.262, grifo no original). Outro objetivo é socializar resultados e reflexões acerca da relevância do Programa ou ações similares. Tais socializações estão sendo feitas através da mídia - TV e rádio -, de participações em eventos - internos e externos - e, ainda, através de exposições em turmas de Letras da FURB.

Quanto à estratégia de inserção nas comunidades, após a escola ter sido selecionada, a Prefeitura entrou em contanto com a direção para formalizar o desenvolvimento dos projetos. A seguir, a extensionista foi à escola para uma conversa com diretores, membros da direção e coordenação. Nesse momento houve uma conversa sobre os objetivos dos Projetos, a metodologia e, ainda, uma breve explicação sobre que é Extensão Universitária, pois se percebeu que o termo "extensão" não era conhecido.

Após conversa com o (a) professor (a) da quarta-série selecionada, partiu-se para a inserção na sala de aula. No primeiro contato com as turmas de quartas-séries, os alunos responderam a um questionário, o qual possui sete perguntas, dentre elas, três foram mais relevantes: (1) "Qual é o nome da rua onde você mora? Por que ela tem esse nome?” (2) "Você sabe um pouco da história de sua escola? Quantos anos ela tem? Por que ela tem esse nome? Conte o que souber." e (3) "Você sabe como seus pais se conheceram? Se souber, conte a história.". As duas primeiras questões se referem ao Projeto Ler e escrever histórias de comunidades, e a terceira, ao projeto Ler e escrever histórias familiares.

Quanto ao desenvolvimento do projeto Ler e escrever histórias de comunidades, após diagnosticar o quanto as crianças conhecem sobre suas escolas e ruas, elas são convidadas a ingressar no universo da pesquisa. Após uma semana, trazem outras informações, iniciando a produção do gênero relato-histórico. Elas leem, todos comentam e entregam (a data de entrega não é rígida). Somente com a entrega de ao menos algumas produções, por mais simplificadas que sejam, é que acontece a intervenção, ou seja, os materiais coletados são levados à sala de aula. Os materiais utilizados são selecionados pela extensionista e, no último de 2008, também por acadêmicas voluntárias do curso de Letras. Tal coleta se dá no Arquivo Histórico José Ferreira da Silva, na cidade de Blumenau, na forma de publicações locais. Essas publicações revelam, de forma resumida, a biografia de quem a escola leva o nome, narram o histórico da escola, entre outros. Ao término da leitura dos materiais, os alunos têm espaço para comentar, debater e questionar sobre o tema e sobre o que chamou a atenção. 
No projeto Ler e escrever histórias familiares, após diagnosticar, através do questionário, o quanto as crianças conhecem sobre as histórias familiares, exemplos são utilizados, como forma de os alunos perceberem as particularidades do gênero. E, novamente, os alunos iniciam outra produção, havendo o prazo de uma semana para a entrega (o prazo não rígido).

Durante todo o processo, os (as) professores (as) mantiveram-se em sala, fizeram perguntas e interagiram - com a extensionista, os alunos e com os materiais utilizados. Por esse motivo é que se considera que, além do público-alvo, os alunos, também as professoras das turmas também sejam um público indireto; por estarem acompanhando um trabalho que segue de duas a três vezes por semana, durante o período de, mais ou menos, três meses.

\section{RESULTADOS E ANÁLISE}

Quanto à apresentação de resultados alcançados pelo Programa "Sentidos para atividades de leitura e escrita na escola", há alguns que são difíceis de serem mensurados ou apresentados. Botomé (1996) cita que algumas contribuições próprias da natureza da Universidade podem acabar sendo esquecidas por serem mais sutis - dificultando que sejam notadas ou detectadas - ou, ainda, quando praticadas, pouco ou nada valorizadas. Nas próprias palavras do autor, ele ainda afirma que são "pouco atrativas, na medida que exigem esforços prolongados e processos e mudanças mais profundos e duradouros. E, mesmo, pouco vistosas, do ponto de vista de sua repercussão social e de seu "marketing político". (1996, p.58)

Por qual motivo estão sendo trazidas ao texto tais palavras do autor? O Programa em questão pode apresentar resultados quanto aos textos produzidos pelos alunos (ou seja, o gênero textual) e, ainda, quanto à ampliação dos conhecimentos acerca das histórias familiares e comunitárias - pois é possível comparar o que os alunos relataram saber no questionário (com relação às escolas, pouco, ou quase nada; com relação às famílias, a maioria só sabia onde os pais se conheceram e, com relação às ruas, os alunos criavam, porque o nome as lembrava algo) e os textos produzidos ao longo do desenvolvimento dos Projetos. Porém, a dificuldade está em mensurar o quanto o Programa foi eficiente ao provocar os (as) professores (as). Para tanto, seria necessário acompanhamento a longo prazo e, mesmo assim, não seria garantia alguma, pois o (a) professor (a) poderia estar agindo com base na presença de um "observador". 
Apesar da dificuldade de comprovação, acredita-se que a imersão de professores em um trabalho como esse pode provocar a necessidade de aprimoramento/atualização. Por exemplo: os gêneros relato-interpretativo e relato-histórico são trabalhados com as turmas, e os (as) professores (as) observam isso. Muitas vezes tais profissionais têm formação anterior à inserção da noção de gênero na grade curricular das Universidades onde estudaram - se é que foi inserida.

Focando-se, neste momento, na dimensão institucional, através das ações do Programa, a Universidade tem a possibilidade de conhecer quais materiais escritos estão circulando em sala de aula. Ela também é beneficiada no sentido de o Programa coletar dados empíricos sobre as comunidades, através dos textos. Num trabalho como esse, também se tem a percepção do quanto as comunidades valorizam suas próprias histórias de constituição.

As contribuições nas dimensões institucional e acadêmica estão bastante interligadas. Ocorrem diversas percepções, por parte da extensionista e das voluntárias, e a partir dessas percepções, como consequência, são realizadas as comparações: entre o que se idealiza na academia e o que se encontra nas escolas. Muitas vezes o modelo familiar continua a ser idealizado, e os acadêmicos, posteriormente, acabam tendo um "choque de realidade", pois o momento em sala nem sempre é um preparatório para o momento na comunidade. É possível perceber que "família", atualmente, não se enquadra mais em um modelo ou padrão.

Alguns fatos puderam ser observados com relação a vários alunos nas diversas turmas, tais como: pais que não querem, terem dificuldade ou evitarem, apesar da insistência dos filhos, contar suas histórias familiares; alunos que dizem não querer que outras pessoas saibam sobre suas histórias familiares; alunos que mostram que, antes da pesquisa, não faziam ideia da história familiar ou de constituição familiar - esses alunos costumam dizer "agora eu já sei como meus pais se conheceram" -; alunos que falam timidamente que não moram mais com os pais porque apanhavam ou por outros motivos; enfim, as percepções que a extensionista e voluntárias têm, muitas vezes, vão além do que pode ser lido nos textos das crianças, que se limitam a resumir o que sabem ou descobrem.

Se um povo ou comunidade se afasta de sua história, afasta-se das características que o (a) diferenciava dos (as) outros (as) povos/comunidades. Na própria cidade de Blumenau esse processo pode ser observado: bairros próximos ao centro pouco ou nada preservam as culturas alemã e italiana (sem contar a arquitetura). Nesse sentido, na dimensão social, percebe-se que ações como essa servem como uma ponte entre a história empoeirada/guardada no Arquivo 
Histórico e o lugar de onde essa história adveio, ou melhor, e os que ainda estão imersos nos contextos em que a história se deu. Os textos trabalhados em sala de aula não se referem somente ao nome da escola, mas perpassam por várias questões locais: imigração, perseguição aos alemães durante a guerra, proibição do uso da língua alemã, enchentes, entre outros assuntos locais.

Ainda na dimensão social, outro processo ocorre: não somente a aproximação dos alunos com os materiais escritos, como, também, com os textos orais. Isso se dá no período em que as crianças pesquisam sobre questões familiares e comunitárias. Elas entrevistam membros da família, moradores antigos da rua, entre outros. Transformar esses textos orais em escritos é uma forma de desenvolver a competência linguística: levar em consideração que o interlocutor não está presente no momento da narração; transformar um texto em $1^{\mathrm{a}}$ pessoa em $3^{\mathrm{a}}$ pessoa - do singular ou plural; resumir; ter coesão e coerência, utilizar conectivos; adequar à linguagem formal; entre outros.

Durante a pesquisa, não há uma aproximação dos alunos com as histórias - que, para perdurarem, precisam ser contadas - mas, também, com os contadores de história, uma vez que, segundo Geraldi (1997), é necessário que se tenha o que dizer, que se tenha uma razão para dizer o que se tem a dizer e um interlocutor. Além disso, como salienta Moita Lopes (2001), durante as práticas narrativas, os sujeitos são construídos, assim como constroem os outros e se ligam ao mundo social. Analisar tais narrativas seria ter "acesso à socioconstrução das identidades sociais" (MOITA LOPES, 2001, p. 63).

Apresentar dados não é o objetivo deste artigo, pois ainda foram superficialmente analisados. Algo que também não pode ser observado nos textos escritos, pois foram falas espontâneas e em momentos inesperados, foi o fato de as crianças, referindo-se a elas mesmas (nascimento, crescimento, personalidade), recuperavam algo da narrativa da avó, do avô, do pai ou da mãe - "ele disse que eu...", “ela me contou que eu...". Kehl (2005) afirma que "é o reconhecimento do outro que nos confirma que existimos e que somos (mais ou menos) os mesmos ao longo da vida, na medida em que as pessoas próximas continuam a nos devolver nossa "identidade".

Mais do que dominarem os gêneros textuais relato-histórico e relato-interpretativo, ou seja, indo além das dimensões do gênero definidas por Bakhtin - conteúdo temático, estrutura composicional e estilo -, há outro aspecto a se considerar. De acordo com Silveira (2002, p. 19), os textos são produzidos "a partir de discursos e de linguagens [...] que não apenas (e não 
principalmente) 'expressam' e ‘comunicam' - como as análises clássicas das funções da linguagem nos ensinavam - mas também 'constroem' e 'constituem' a realidade”.

\section{CONSIDERAÇÕES FINAIS}

Como dito no início do artigo, esse Programa se apoia na concepção de extensão como sendo uma "comunicação com a comunidade". Muitas vezes a Universidade, através da extensão, pode cair na armadilha de querer ser a provedora do saber, abrindo-se pouco para transformar a si mesma nesse processo. Dessa forma, seus agentes podem ir a campo com capacidade limitada para perceber o quão pouco a Universidade conhece sobre a comunidade em que está inserida.

Percebeu-se a relevância de socializar as ações. Através da mídia e eventos internos e externos à Universidade, a comunidade, como um todo, também é convidada a refletir sobre os processos de apropriação da escrita e respondeu, até então, muito bem a isso. A socialização torna acessíveis as compreensões alcançadas com base no que foi vivido na comunidade, lançando, ainda, novas problematizações.

Se a escola privilegia a leitura e produção de textos com base no livro didático, parece não levar em consideração as relações que a criança tem além dos muros da escola - que, no caso de uma criança de quarta-série, pode, muitas vezes, resumir-se às relações em casa e na rua. Se os contextos de interação das crianças resumem-se a esses contextos (casa, rua e escola), a escola, através das atividades de produção de texto, pode criar condições para os sujeitos significarem essas relações e experiências, percebendo-se, assim, como parte integrante desses contextos. Além disso, a produção de texto nessa perspectiva permite a troca de experiências. Mesmo crianças de quartas-séries têm experiências. Não havendo espaço para que essas experiências sejam divididas, pode-se entender que, quando o sujeito entra na sala de aula, ao mesmo tempo deixa as experiências do lado de fora. Parece que ele não continua, ele começa.

\section{REFERÊNCIAS}

BAKHTIN, M. Estética da criação verbal. Tradução Paulo Bezerra. 4. ed. São Paulo: Martins Fontes, 2003. 
BOTOMÉ, S. P. Pesquisa alienada, ensino alienante: o equívoco da extensão universitária. Petrópolis: Vozes, 1996.

FREIRE, P. Extensão ou Comunicação? 10. ed. Rio de Janeiro: Paz e Terra, 1977.

GERALDI, J. W. Portos de passagem. 4. ed. São Paulo: Martins Fontes, 1997.

KEHL, Maria Rita. Com o outro no corpo: o espelho partido. Disponível em $<$ http://secrel.com.br/JPOESIA/mariakehl1.html $>$. Acesso em: 30 de janeiro de 2009.

MACHADO, R. Entre o público e o privado: gestão do espaço e dos indivíduos em Blumenau (1850 - 1920). Blumenau: Edifurb, 2008.

MOITA LOPES, Luiz Paulo da. Práticas narrativas como espaço de construção das identidades sociais: uma abordagem socioconstrucionista. In: RIBEIRO, Branca Telles; LIMA, Cristina Costa; DANTAS, Maria Tereza Lopes (Org.). Narrativa, identidade e clínica. Rio de Janeiro: Edições IPUB/CUCA, 2001.

PIAGET, J. (1954) Intelligence and affectivity: their relationship during child development. Annual Reviews, Palo Alto-CA, (ed.USA, 1981).

SILVEIRA, Rosa Maria Hessel. Textos e Diferenças. Leitura em Revista. Ijuí. Associação de Leitura Brasil Sul, n.3 jan//jun 2002. 